Revista Iberoamericana, Vol. LXXIII, Núm. 221, Octubre-Diciembre 2007, 745-758

\title{
LLÉVESE LA CÁMARA A LA TUMBA: DESEO FOTOGRÁFICO EN CUATRO CUENTOS DE LUGONES
}

\author{
POR \\ VALERIA DE LOS RÍOS \\ Universidad Diego Portales, Chile
}

El primer equipo de daguerrotipia que llegó a Latinoamérica lo hizo a bordo del buque-escuela francés L'Orientale. Éste desembarcó en Bahía, Brasil, el 17 de enero de 1840, para continuar luego hasta Montevideo, Uruguay. El barco no se detuvo en Buenos Aires -destino obligado de la mayoría de las embarcaciones provenientes de Europa-debido a un bloqueo económico motivado por quejas de ciudadanos franceses en contra del gobierno de Juan Manuel de Rosas. Mariquita Sánchez, viuda de Thompson fue uno de las testigos de la demostración realizada en Montevideo en 1840. En una carta a su hijo Juan, residente en Buenos Aires, describe con entusiasmo esta nueva tecnología:

\begin{abstract}
Ayer vimos una maravilla, la ejecución del daguerrotipo es una cosa admirable, imaginate una cámara obscura en la que se coloca la plancha ya preparada con los ingredientes, la plancha es como de plata muy brillante, colocada se pone la dirección que quieres y a los seis minutos la sacan de allí encerrada de un modo que no se pueda ver; y la ponen en otra preparación con el termómetro con los grados de calor que son necesarios y después de todas esas precauciones, te ves la plancha como si hubieras dibujado con lápiz negro la vista que has tomado, con tal perfección y exactitud que sería imposible obtener de otros modos. (Becquer 14)
\end{abstract}

Sánchez refiere el acontecimiento como una experiencia sorprendente, casi mágica. Luego, intenta hacer una descripción detallada del método que hace posible la impresión de la imagen, destacando de esta manera la concepción científica del procedimiento. Finalmente, hace una comparación con una técnica de reproducción en blanco y negro, similar al dibujo, pero que lo supera a éste y a cualquier otro medio en exactitud y perfección.

Cruzando por el estrecho de Magallanes, L'Orientale llegó a Valparaíso en mayo de 1840, para luego continuar al Perú. Pero el viaje se vio interrumpido cuando el navío chocó con unas rocas a la altura de Punto Buey, y se hundió. Todos los pasajeros y el equipo fueron salvados, y los estudiantes de a bordo retornaron a Europa en barcos comerciales (McElroy 4). La trunca historia de esta primera llegada cifra ciertas tensiones continentales en relación a la tecnología. La fotografía llegó como una novedad foránea que, una vez anunciada, desapareció, permaneciendo meramente sugerida, inalcanzable y por supuesto, doblemente deseada. Esta duplicidad del deseo se explica porque Françoise Arago, 
astrónomo y físico que presentó la invención de Daguerre ante la Academie des Beaux Arts y la Academie des Sciences, ya había expresado que la fotografía llevaba -incluso desde antes de sus inicios- el componente del deseo: "There is no one who has not ardently desired some means to fix images of their own accord” (Batchen 53). Geoffrey Batchen asegura que hubo más de veinticinco inventores de siete países ${ }^{1}$ diferentes que intentaron fijar las imágenes de la cámara oscura entre 1790 y 1839.

La fotografía llegó a Latinoamérica sólo un año después de que su invención fuera anunciada oficialmente en Francia. Este hecho ocurrió en un momento particular de la historia del continente, cuando la mayoría de los países cumplía las primeras décadas de vida independiente, luego de los procesos de autonomización. Los primeros años de la fotografía coinciden, entonces, con los primeros años de vida de las naciones latinoamericanas. Por ello no es raro que temas originados a raíz de la fotografía-es decir, problemas de identificación, reproducción y de copias versus originales- surgieran y se entremezclaran con cuestiones de formación y de identidad nacionales. A fines del siglo XIX y durante las dos primeras décadas del nuevo siglo, cuando muchas de las naciones latinoamericanas celebraban su centenario, algunos escritores latinoamericanos empezaron a incorporar estos nuevos temas a la literatura, creando una curiosa fusión entre ciencia, tecnología y ficción. La aparición de la fotografía en literatura demuestra un profundo deseo por apropiarse de esta nueva tecnología, y paradójicamente, un miedo inexplicable ante las consecuencias de esta apropiación. Los cuentos de Leopoldo Lugones aquí analizados trabajan temas específicos relacionados con la introducción de esta tecnología, como los desplazamientos temporales y propiamente tecnológicos que ésta provoca. Además, estas ficciones tematizan la relación con otras técnicas de reproducción como la silueta, y con géneros específicos como la fotografía antropológica, el retrato criminal y médico. También, estos textos elaboran cuestiones propiamente fotográficas, como el tema del desvanecimiento de las imágenes y la problemática de la pose.

Después del primer y novedoso contacto con el daguerrotipo, que tuvo un final abrupto con el hundimiento de L'Orientale, se produjo una rápida diseminación de la técnica. En un comienzo, ésta estuvo en manos de fotógrafos itinerantes, provenientes principalmente de Europa y Estados Unidos. ${ }^{2}$ Tal como lo afirma Ronald Kay, la llegada de la fotografía a Latinoamérica produjo una discontinuidad temporal, provocada por la superposición de al menos dos temporalidades históricas diferentes: primero, el tiempo de la máquina en el contexto metropolitano en que ésta fue creada, y segundo, el tiempo de las ex colonias, en las que este nuevo aparato se insertó. Para este autor, la fotografía

${ }^{1}$ Siete franceses: Niépce, Bayard, Daguerre, J. B. Dumas, Desmarets, Vérignon, Lassaigne; seis ingleses: Talbot, J. B. Reade, Herschel, Fyfe, Mungo, Ponton; seis alemanes: Steinheil, Kobell, Breyer, Hoffmeister, Von Wunsh, Liepmann; un norteamericano: Samuel F. B. Morse; un español: Zapetti; un noruego: Winther; un suizo: Gerber, y un brasileño: Hercules Florence (Batchen 35). ${ }^{2}$ El estadounidense Augustus Morand instaló un estudio en Río de Janeiro en 1842. Ese mismo año, el barón Jean Baptiste Louis tomó el primer daguerrotipo en Bogotá; el comerciante norteamericano John Armstrong Bennet inauguró la primera galería de daguerrotipos en Montevideo; y el francés Maximiliano Danti estableció su estudio en Perú. En 1843 se introduce en Buenos Aires el primer equipo fotográfico. Ese mismo año, el francés J. P. Deviette instaló un estudio en Valparaíso y en 1845, los americanos Carlos y Jacobo Ward hicieron lo mismo en Santiago, Valparaíso y Copiapó. 
funcionó como un acto de posesión, que "tomó” literalmente la imagen del continente. Este acto de ocupación ocurre en parte porque en el contexto latinoamericano no existía una tradición pictórica consolidada, ${ }^{3}$ por lo que la máquina fotográfica usurpó la posibilidad de que el continente se creara una imagen propia. A pesar de que esta noción de inserción desplazada es plausible, es importante tener en cuenta que la tecnología fotográfica fue recibida con alegría e incorporada rápidamente por las sociedades latinoamericanas. Es por eso que quizá sea más interesante observar los desplazamientos producidos por esta incorporación, en lugar de denunciar la presencia de esta técnica foránea.

Los años de introducción y popularización de la fotografía en Latinoamérica (18401880) coinciden, a nivel mundial, con el choque y la fusión de dos tendencias ideológicas aparentemente contrarias: el romanticismo y el positivismo. Tal como observa Reese Jenkins, el romanticismo aportó una interpretación básica de la naturaleza como el lugar de encuentro de fuerzas opuestas, metáfora extraída de la concepción polar de la electricidad. Esta oposición esencial es la que inspiró a William Henry Fox Talbot a llamar “positivo-negativo" al proceso de reproducción fotográfico inventado por él. Pero la ciencia romántica, identificada con la Natursphilosophie, fue criticada y acusada de especulativa (20). El positivismo, basado en la experimentación y en la observación, se convirtió en la forma científica dominante en la segunda mitad del siglo xix. La fotografía fue adoptada por éste, a modo de herramienta útil para documentar y analizar, aunque los inventores -a juicio de Jenkins- se mantuvieron románticos y positivistas al mismo tiempo:

How is this possible? They were epistemological positivists and ontological Romantics. The positivist scientists were empiricists in the methods of acquiring knowledge, but they were unable to shed their Romantic views of nature: 1) seeing the world composed of forces that were interrelated and ultimately unified; and 2) seeing the world not as a static entity that was only once created, but as an evolving, changing, and continuously created entity. (20)

El espíritu romántico de los numerosos inventores de la fotografía quedaba expresado en la misma forma en que éstos denominaron o describieron los primeros procesos fotográficos, refiriéndose, por ejemplo, a la cámara como "espejo" o "pincel de la naturaleza”. A pesar de que la invención despertó un interés generalizado, la técnica en sí estuvo disponible al principio sólo para algunos fotógrafos amateurs con cierto poder adquisitivo, y para algunos científicos. Keith McElroy afirma que hacia 1857 en Latinoamérica un retrato fotográfico de 1/6 equivalía al precio aproximado de cuatro libras de carne (58). Teniendo en cuenta que el trabajo manual durante el siglo xix no era bien

\footnotetext{
${ }^{3}$ Esta afirmación puede aplicarse también a Estados Unidos, donde tampoco existía una tradición pictórica fuertemente arraigada, y donde la fotografía ocupó un lugar central. Gisèle Freund afirma que entre 1840 y 1860 esta "joven nación se sentía orgullosa de sus logros, y encontraba en la fotografía un medio ideal para inmortalizarse” (31). La diferencia con las ex colonias americanas radica quizás en que, a diferencia de éstas, Estados Unidos sí se constituyó en un foco de producción de tecnología fotográfica.
} 
pagado, este valor representaba un costo excesivo para una familia de clase trabajadora. Al igual que en Europa, la fotografía no fue un medio popular hasta la introducción de las cartes-des-visite. Alrededor de 1853, el fotógrafo y empresario francés André-Adolphe Disdéri se dio cuenta de que la fotografía estaba disponible sólo para un número reducido de público, y que el gran formato de moda en ese entonces hacía costoso el producto final, tanto para el fotógrafo como para el fotografiado (Freund 55). Disdéri tuvo la ingeniosa idea de reducir el tamaño de las fotografías, haciendo posible un negativo con una docena de exposiciones idénticas por un quinto del precio habitual. Él patentó su invento en 1854, pero éste no se hizo realmente famoso hasta 1859, cuando el emperador Napoleón III se detuvo frente a su estudio en París para fotografiarse. Ya en 1860, un columnista del diario El Comercio de Lima comentaba la popularidad del uso de "cartas de visita”. A partir de esos años, comenzó a ser común que ciertas casas latinoamericanas se transformaran en una galería fotográfica, con álbumes lujosos, llenos de cartas de visita. Según McElroy, esta práctica reflejaba a las sociedades y sus valores, mejor que cualquier otro arte de la época (15). Siguiendo la descripción de Freund, esta simple innovación democratizó el retrato: reyes, burócratas, científicos, artistas, sirvientes, ricos y pobres, todos eran iguales frente al lente de la cámara. En el caso de las sociedades latinoamericanas, las "cartas de visita” también reflejaban las aspiraciones y las fantasías de los ciudadanos, y su deseo de ser iguales al resto del mundo (McElroy 53). Si bien el aspecto democratizador de la fotografía fue celebrado por las sociedades latinoamericanas, pronto surgieron otros usos de la fotografía, como la fotografía de viaje, la fotografía médica, y la criminal, que expandieron los límites de la técnica y contribuyeron a producir ansiedad en el sujeto decimonónico.

Durante la década de 1880, Argentina pasaba por una situación económica bastante favorable. El mercado privilegiaba materias primas producidas en ese país, como la carne y los cereales. Como consecuencia, se creó riqueza, pero al mismo tiempo, cualquier intento de industrialización se frenó. El presidente Julio Argentino Roca era un defensor tanto del liberalismo como del positivismo. Una de las metas de su gobierno era la modernización del país, que se realizaría a través de la educación pública, la migración europea, la extensión de los ferrocarriles y de los sistemas telegráficos, además de la introducción de tecnología al trabajo agropecuario y la incorporación del desierto al mundo productivo. Buenos Aires a fines de siglo fue escenario de cambios profundos, relacionados con este proceso de modernización. Fueron precisamente estos cambios entre ellos, la fuerte inmigración extranjera- los que motivaron cuestionamientos en cuanto a la tradición, la identidad y el futuro de la nación. En este contexto, empezaron a aparecer en literatura algunos problemas relacionados con la reproducción mecánica. Por ejemplo, espíritus y fantasmas comenzaron a poblar la producción literaria, junto con temas científicos y seudocientíficos como el espiritualismo, el magnetismo, la hipnosis, el mesmerismo, la frenología, la fisonomía, e incluso la histeria, basada en los experimentos -documentados fotográficamente- de Charcot.

El escritor argentino Leopoldo Lugones trabajó bajo estas influencias. En su introducción a los Cuentos fantásticos Pedro Luis Barcia menciona el interés científico de este autor, que se traspasará más tarde a su ficción fantástica. Según Barcia, el propio Lugones escribió ensayos sobre botánica, zoología, arqueología y matemáticas (13). Su 
ensayo "El tamaño del espacio", por ejemplo, fue originalmente una conferencia dictada en la Facultad de Ciencias Exactas, Físicas y Naturales, tal como lo menciona Arturo García Ramos en su introducción a Las fuerzas extrañas. La relación directa de Lugones con la fotografía es incierta. Se sabe que fue él quien invitó Horacio Quiroga como fotógrafo en su viaje a las misiones jesuíticas durante las primeras décadas del siglo (Sarlo $30)$.

En su cuento “Un fenómeno inexplicable” (Las fuerzas extrañas, 1906), un anónimo narrador en primera persona cuenta una historia ocurrida once años atrás. Él se encontraba viajando por las provincias agrícolas de Córdoba y Santa Fe, y tratando de evitar las rústicas tabernas de la zona, terminó por hospedarse en la residencia de un inglés viudo, que vivía completamente solo. El viajero describe a su llegada un paisaje que mezcla tanto elementos rurales como modernos, generando más que una escena pictórica, un escenario productivo en el que destaca la ausencia del trabajo humano:

Nada tenía de atrayente el lugar. La estación con su techo de tejas coloradas; su andén crujiente de carbonilla; su semáforo a la derecha, su pozo a la izquierda.

En la doble vía del frente, media docena de vagones que aguardaban la cosecha. Más allá el galpón, bloqueado por bolsas de trigo. A raíz del terraplén, la pampa con su color amarillento como un pañuelo de yerbas; casitas sin revoques diseminadas a lo lejos, cada una con su parva al costado; sobre el horizonte el festón de humo del tren en marcha, y un silencio de pacífica enormidad entonando el color rural del paisaje. (126)

El lugar descrito no representa en ningún caso una proyección romántica del interior del personaje, sino que más bien enmarca un espacio de producción, que es específicamente agrícola. En él los productos son extraídos para ser luego trasladados a un lugar lejano, hecho demostrado por la presencia de los vagones y el humo del ferrocarril en el horizonte. El narrador es un observador interesado en la "fisonomía” de la pradera (un estudio científico o seudocientífico de ésta) y en la tarde silenciosa donde destaca el chalet “industrioso" (126) -es decir, potencialmente productivo- de su anfitrión. La casa tenía "una especie de triste dulzura, algo de sepulcro nuevo en el emplazamiento de un antiguo cementerio" (126). Destaca el carácter mortuorio de la descripción de la residencia del inglés y del pueblo en general, marcado por el silencio y un estado generalizado de quietud. El inglés, por su parte, es descrito físicamente de manera detallada: “Cabeza elevada y calva, rostro afeitado de clergyman; labios generosos, nariz austera” (127). Más que presentar las características del personaje, la descripción minuciosa es un reporte cuasi científico de sus facciones: "Sus protuberancias superciliares equilibraban, con una recta expresión de tendencias impulsivas, el desdén imperioso de su mentón. Definido por sus inclinaciones profesionales, aquel hombre podía ser lo mismo un militar que un misionero" (127). El narrador se revela como un connosseur de la fisonomía, una ciencia -o seudociencia- que se dedicaba a estudiar la forma del cráneo humano para determinar el carácter de la persona, considerando aspectos morales y éticos. Tal como sostiene Deborah Poole, la moda de la fisonomía coincide en Latinoamérica con la popularidad de las "cartas de visita”. La fisonomía otorgaba -según Poole- un vocabulario listo para interpretar los nuevos retratos fotográficos (111). La relación entre fotografía y fisonomía era tan estrecha, que Disdéri, al preparar un salón en que sería expuestos los padres de la 
fotografía, incluyó un medallón con el retrato de Giambattista della Porta, uno de los pioneros de la fisionomía en el siglo xviI.

En el cuento de Lugones, tanto el narrador como el inglés solipsista son hombres interesados en la ciencia de la época. Ambos son homeópatas (128), y discuten interesadamente aspectos relacionados a esa y otras ciencias, nombrando a varios científicos y sus experimentos. ${ }^{4}$ Mientras discuten un error supuestamente provocado por alucinaciones, el anfitrión comienza a relatar una experiencia que le ocurrió a él personalmente alrededor de 1858, cuando como oficial militar visitó la India. En ese país había conocido a algunos yoghis, a quienes fotografió. El testimonio del hombre -que según el narrador estaba marcado por un fuerte acento extranjero-apuntaba a la veracidad de los poderes de estos hombres: "la placa reprodujo todo, tal cual yo lo había visto. La alucinación resultaba así imposible, pues los ingredientes químicos no se alucinan...” (131). La fotografía es avalada aquí como documento científico y, como tal, funciona como prueba irrefutable de los hechos. El proceso químico del revelado otorga la base a la argumentación de la fotografía como testimonio.

Encandilado por las proezas de los yoghis, el inglés quiso adquirir sus mismos poderes y en poco tiempo logró algunos. Pero junto con ellos apareció también una inquietud creciente, como si algo adverso se hubiera filtrado dentro de su propio cuerpo. Al hablar, el inglés utiliza la palabra "desdoblamiento" (132) para describir su mal. Y confiesa que queriendo “ver qué era lo que salía de mí, siendo yo mismo” (132), se dispuso a esperar a su doble después de la rutina de meditación. Allí vio la forma de un mono, que desde entonces lo seguía a todas partes:

Desde entonces no se aparta de mí. Lo veo constantemente. Soy su presa. A donde quiera él va, voy conmigo, con él. Está siempre ahí. Me mira constantemente, pero no se le acerca jamás, no se mueve jamás, no me muevo jamás... (132)

El terror a la duplicación (a la reproducción) se manifiesta incluso a nivel gramatical. Al comienzo del párrafo, existe una división clara entre el yo y el otro, entre el hombre y la bestia, pero más tarde la confusión en el narrador se hace evidente en el uso de conjugaciones verbales correspondientes a la primera y tercera persona del singular, y en el uso de sus correspondientes pronombres. La división del sujeto se manifiesta así a nivel lingüístico. El mismo inglés reconoce haber perdido el concepto de unidad del yo. Pero esta división se expresa también a nivel óptico, visual, cuando cuenta que a veces ve cosas dobles "porque cada ojo procede sin relación con el otro..." (133). El síntoma recién esbozado corresponde a una descripción de la visión binocular o estereoscópica, uno de los descubrimientos más importantes del siglo XIX, en cuanto a la visión. En lugar de la perspectiva única de la cámara oscura y de la cámara fotográfica (cada una de las cuales genera un cono de visión único e independiente), cada ojo humano difiere del otro en cuanto a lo que ve. De ahí que una vez inventada la fotografía, proliferaran tanto en Europa

\footnotetext{
${ }^{4}$ Entre ellos: Rutter, Leger, Reichenbach (químico y filósofo naturalista alemán, descubridor de la parafina) y Crookes (físico inglés que estudió la electroscopia, el peso molecular y los rayos catódicos). De los dos primeros no se han encontrado referencias.
} 
como en Latinoamérica los visores estereoscópicos, ${ }^{5}$ que creaban la ilusión de profundidad en el observador.

La utilización de la figura del mono por parte de Lugones no es casual y se relaciona en parte con la popularidad del darwinismo en la Argentina de fines de siglo. ${ }^{6}$ En 1872, Charles Darwin publicó The Expression of the Emotions in Man and Animals, un estudio que privilegió el uso de la fotografía para explicar las expresiones humanas, que establecían un vínculo entre humanos y animales. Por otra parte, la utilización de simios en el imaginario simbólico y cultural europeo es un tópico estudiado, que ha llevado a teóricos como Donna Haraway a hablar de un “orientalismo simiesco", que surge en el contexto del colonialismo decimonónico. Haraway sostiene que este tipo de producción demuestra cómo el sujeto occidental es construido a partir de un "otro" en términos de especie, raza y sexo (11). Siguiendo las premisas de Haraway, Anne McClintock propone que durante la era victoriana el cuerpo del primate se convirtió en un espacio simbólico para reordenar y establecer márgenes entre lo humano y lo natural, lo femenino y lo masculino, la familia y lo político, el imperio y la metrópolis (311). En este contexto, los monos aparecían como aliados de las clases peligrosas -los pobres, los trabajadores, los criminales, los enfermos y las mujeres obreras-, sospechosos todos de degeneración racial. De este modo, el mono emerge como una imagen contradictoria, que encarna por una parte la esperanza del progreso imperial a través del comercio, y por otra, el miedo ante los excesos coloniales (312).

El narrador de "Un fenómeno inexplicable” intenta tranquilizar al inglés y para ello le propone un experimento. Le ofrece dibujar su silueta para demostrarle que su sombra es perfectamente humana y no la de un simio. La silueta como técnica de retrato es un precedente del retrato fotográfico. Su clímax se produjo en Francia alrededor de 1750 y según Freund, era una técnica abstracta que no requería experiencia específica del realizador (al final del cuento, el narrador confiesa que no sabe dibujar). Concedido el permiso por el extranjero, el narrador fija en la pared un papel con cuatro migas de pan mojado. Luego, procede a trazar la silueta, "sin levantar la mano” (134) y sin fallar el pulso en el trazado. El resultado es el más temido, puesto que en el papel surge el contorno del mono. El uso de la silueta en este cuento de Lugones da cuenta de un desplazamiento temporal significativo desde el punto de vista tecnológico. La fotografía como técnica estaba disponible para el colonialista inglés en la India de 1858, y podía ser utilizada como prueba científica de los procedimientos de los yoghis. Sin embargo, en la Argentina industriosa pero rústica de principios del siglo xx, sólo se dispone de un papel, lápiz, luz y cuatro migas de pan para documentar la imagen del sujeto en estudio. A pesar de la inexperiencia del dibujante, la silueta es tomada como evidencia de que el relato del inglés era cierto.

\footnotetext{
${ }^{5}$ Estos aparatos fueron especialmente populares alrededor de $1850 \mathrm{y}$ eran utilizados principalmente para la fotografía de viaje (Clarke 239).

${ }^{6}$ Gioconda Marún ha estudiado la presencia del darwinismo en la literatura argentina. On the Origins of Species by Means of Natural Selection fue publicado en 1859 y tuvo un gran impacto en ese país, debido en parte a que algunos de los datos publicados en ese libro habían sido obtenidos en Argentina durante el viaje que Darwin realizó a bordo del "Beagle". Este hecho llevó a proclamar al que fuera presidente de la república, Domingo Faustino Sarmiento, que el darwinismo era argentino.
} 
“Un fenómeno inexplicable” presenta una versión particular del tópico civilización y barbarie. Un inglés, personificación de la cultura europea, viaja a la India, donde se convierte en un semibárbaro al incorporar a un animal como parte de sí mismo. La presencia fantasmal del mono expresa en parte el fracaso de la empresa imperialista. El inglés siente horror ante su subjetividad dividida, que integra a un "otro" abyecto como parte de sí mismo. Esta criatura híbrida viaja alrededor de 1888 a la Argentina, un país que en ese entonces era foco de la migración europea. Este país funciona como un refugio, alejado de la metrópolis en un doble sentido: alejado de Europa y de Buenos Aires, puesto que el personaje se ubica en un espacio rural. Sin embargo, el campo no representa un locus amoenus clásico, sino más bien un territorio productivo, asociado al progreso y a la modernización (la migración extranjera era vista como una forma de modernizar al país), del que se extraen materias primas para ser exportadas a las metrópolis.

En el cuento de Lugones “El espejo negro” de 1898, un científico -el doctor Paulínle presenta al anónimo narrador un objeto muy especial. Se trata de un espejo negro, hecho de carbón, que en tiempos remotos era utilizado por brujas para producir efectos mágicos. Basándose en datos científicos, Paulín concluye que el espejo -que él denomina "placa" (126)-conduce la electricidad. Como él sostiene que el pensamiento humano es una forma de electricidad, cree que al aplicar el pensamiento al espejo, éste debería reflejar la imagen de la persona que en ese momento está en la mente del observador. El narrador explica que está dispuesto a experimentar frente al espejo, siempre y cuando el doctor no lo hipnotice. La habitación en que se ubica para realizar el experimento está iluminada y en silencio, como en una fotografía. Involuntariamente, el narrador recuerda a un criminal muerto. De repente, la imagen del convicto empieza a aparecer. El narrador describe el evento como una visión del infierno. El horror que surge en él se relaciona con la mirada del condenado: "Un horror de eternidad vagaba en la mirada del aparecido, que me envolvía sin verme; mirada de vidrio cuya fijeza expresaba soledades enormes” (129). El “otro” fotografiado no devuelve la mirada al observador, porque está fija, como en una fotografía. Esta “mirada de vidrio” podría ser asociada técnicamente a los daguerrotipos, que luego de ser impresos debían ser cubiertos con vidrio para que la superficie no sufriera daños. Este tipo de mirada también podría leerse metafóricamente como una marca de muerte. El narrador de Lugones expresa aquí el temor de tener el retrato de un muerto: ¿retiene una fotografía algo de esa persona ya desaparecida? Lugones juega con esa idea, pero también propone otra: que existe una fuerza desconocida en el observador. La imagen proyectada en el espejo no es voluntaria y no puede ser controlada. En este sentido, el proceso fotográfico escaparía el ideal positivista de una reproducción fiel de la realidad (los deseos inconscientes también son capturados por la cámara), y esta premisa estaría también avalada por la fusión de elementos mágicos y científicos en este cuento. Que el fotografiado sea un criminal tampoco es una casualidad. Durante la década de 1880, el criminólogo francés Alphonse Bertillon desarrolló un sistema de identificación de criminales que empleaba la fotografía y el retrato hablado como su base, utilizando además el lenguaje de la fisonomía. Así, el cuerpo del criminal quedaba inscrito y clasificado dentro de una base de datos que facilitaba su control. "El espejo negro” reitera esta noción de la reproducción de la imagen de sujetos sospechosos para la sociedad. 
Tal como sugerí anteriormente, poco después de su invención, la fotografía se convirtió en una metáfora para una visión positivista del mundo. Según numerosos historiadores de la fotografía, ésta nació en la confluencia de las demandas de la ciencia y del arte, en la búsqueda de un modo de representación transparente y directo. El inventor Samuel Morse, por ejemplo, comparaba la imagen producida por un daguerrotipo con las características pictóricas de un Rembrandt, al mismo tiempo que con las imágenes obtenidas a través de un microscopio o un telescopio (Batchen 138). Siguiendo las exigencias tanto de la ciencia como del arte, se desarrolló durante la segunda mitad del siglo XIX la fotografía de viaje. La primera colección de álbumes, las Excursiones daguerrienes, fueron publicadas entre 1840 y 1844, con ciento veinte vistas de los cuatro continentes (Sougez 90). La fotografía arqueológica también formó parte de este movimiento, centrada principalmente en Egipto y en las civilizaciones precolombinas recién redescubiertas. Malek Alloula-refiriéndose a los apectos coloniales de la fotografía y la industria postal- ha afirmado que la fotografía de lugares distantes, especialmente en la forma de postales, creó una ilusión de proximidad que al mismo tiempo, enfatizó la discontinuidad del espacio y tiempo fotografiados (318). Imágenes de sitios exóticos empezaron a circular rápidamente tras la invención de la fotografía, produciendo un nuevo objeto de estudio, de exposición y de intervención. Alloula afirma que la fotografía de viaje estaba disponible para turistas, soldados y colonizadores, y que funcionaba como un seudoconocimiento de la colonia, que fertilizaba la visión colonial (318).

Es probable que esta proliferación de imágenes influyera en el cuento "Los ojos de la reina” de Lugones, publicado en 1923. En él se cuenta una historia relacionada con Egipto, cuando los primeros “descubrimientos” arqueológicos se estaban llevando a cabo. Mr. Neale, un inglés que trabajaba para los ferrocarriles argentinos, se suicida. Mansur bey, un egipcio que vive en Argentina y se dedica el comercio de diamantes, le cuenta al narrador que la muerte de Mr. Neale era su destino. Neale había participado en descubrimientos arqueológicos en Egipto, lo que explicaría la predestinación de su trágica muerte. Mansur bey revela además que otras dos personas - unos exploradores- murieron antes que Neale por la misma causa: el hallazgo de un espejo en una tumba egipcia. Al mirarlo, el misterioso espejo no reflejaba la cara del observador, sino la de Hatshepsut, una antigua reina egipcia. Del mismo modo en que una fotografía es capaz de congelar el tiempo en un pedazo de papel sensible, el espejo egipcio puede eternizar el rostro de la reina muerta. Esta es una característica propiamente fotográfica, que Lugones adapta a un objeto prefotográfico: el espejo. André Bazin ha afirmado en cuanto a la relación entre fotografía y temporalidad, que "photography does not create eternity, as art does, it embalms time, rescuing it simply from its proper corruption” (14). De este modo, la fotografía funcionaría como una máquina del tiempo, capaz de extraer momentos extáticos del flujo normal de los acontecimientos, para ser traídos luego a otro contexto espaciotemporal.

Fascinados con el reflejo de la hermosa mujer, los exploradores descubren que la imagen se desvanece paulatinamente y deciden perpetuarla fotográficamente. La fotografía que toman muestra el proceso de desvanecimiento de la imagen, que finalmente desaparece del espejo. Tal como se mencionó anteriormente, la empresa fotográfica comenzó como un deseo de fijar la imagen producida por una cámara obscura. Alrededor de 1790 Thomas 
Wedgwood realizó experimentos al respecto, pero acosado por una enfermedad, murió sin hacer conocida su investigación. El problema del procedimiento de Wedgwood era su baja sensibilidad, y que la imagen obtenida no era lo suficientemente estable. Más tarde, Talbot anunciaría haber descubierto la solución al problema de Wedgwood, pero como explica George Eaton, aun en el proceso de Talbot la impresión es muy sensible a la luz, puesto que el clorhidro de plata que produce el desvanecimiento de la imagen no es eliminado del todo, sino sólo desactivado (87). Por otra parte, en 1855 la francesa Societé de Photographie comenzó una investigación para estudiar el desvanecimiento de las imágenes fotográficas. Ese mismo año la Photographic Society de Londres estableció un comité cuyo propósito era la búsqueda de métodos de restauración de impresiones desvanecidas (Eaton 88). El desvanecimiento de las imágenes fotográficas se constituía así en un problema central durante las primeras décadas de vida de esa tecnología.

En "Los ojos de la reina” se hace patente el "deseo de fotografiar” puesto que en ella se expresa el deseo de fijar la imagen. La fotografía es deseada como un método de documentación, para dejar testimonio y dar una forma determinada a la realidad. La imagen en el espejo se desvanece, no así la fotografía que eterniza el instante en que la imagen en el espejo comienza a desaparecer. El espejo refleja la imagen de una muerta y la visión de ella disemina la muerte como castigo. Al final del cuento, el narrador está en posesión del espejo fantástico, pero decide donarlo al Museo Etnográfico para evitar la maldición que produce la muerte. La mención del Museo Etnográfico es doblemente interesante, porque por un lado el museo es el lugar donde van a parar los objetos arqueológicos que han sido extraídos-como una fotografía-del contexto al que pertenecen, y por otro lado, al incorporar elementos encontrados en tumbas, el museo se convierte en un cementerio desacralizado, donde piezas de otras culturas encuentran su última morada.

La muerte y la fotografía han sido relacionadas desde los comienzos de esta técnica. Teóricos de la fotografía como Roland Barthes han señalado que la fotografía es la imagen viva de algo muerto (78). Susan Sontag por su parte, sostiene que las fotografías son memento mori, una conjunción espacio-temporal congelada, que ya no existe al momento de la contemplación. Lugones trabaja este tema en “Hipalia”, un cuento de 1907, que relata la historia de una huérfana adoptada por un viejo pariente del narrador. La hermosa joven enloqueció pasando horas en el subterráneo de la casa en que vivía, donde -según decíapodía ver su propia imagen reproducida en un muro blanco, como si fuera un espejo. El anciano vio cómo poco a poco la joven se iba transformando en una aparición que "semejante a un divino fantasma, entraba en su dormitorio con esa lentitud casi flotante de los extáticos" (Cuentos 182). El movimiento lento y espectral de la joven es lo que delata su condición fantasmática. El narrador de "Hipalia" relata así el proceso de transformación de la joven, que la llevó hasta la muerte:

Fuese como evaporando en una progresiva iluminación de belleza, empalideciendo hasta la transparencia, solemnizándose en un silencio de aparición. Cuando falleció, hubiérase dicho que su blancura acababa de escurrírsele del cuerpo como una vaga nube; pues sólo se conoció que estaba muerta, por la amarillez que le sobrevino. (182) 
Si comparamos los gerundios utilizados en este párrafo ("evaporando", “empalideciendo”) y algunos sustantivos relativos a la imagen (“iluminación”, “transparencia”, “blancura”, “amarillez”), es posible notar cómo Lugones da cuenta de un proceso que puede ser fotográfico en su naturaleza, pero invertido. La Hipalia viva se va desvaneciendo gradualmente, como cuando la fotografía pierde la capacidad de fijar lo que el fotógrafo captura a través de su lente. La blancura de Hipalia se pierde, quedando únicamente un tono amarillento, como aquel presente en las fotografías que envejecen. Este aspecto está asociado al problema de la estabilidad de la imagen. Durante la segunda mitad del siglo XIX, muchos de los componentes utilizados para revelar fotografías podían afectar su calidad. Por ejemplo, los papeles utilizados como soportes, los sistemas de sensibilización y el tipo de lavado de las impresiones podían causar cambios en el resultado final. Eaton afirma que las impresiones de albúmina generalmente adquirían un tono amarillo cuando eran expuestas a la luz, luego de ser impresas y procesadas (89). En ese sentido, el cuento de Lugones se relaciona con los aspectos y dificultades materiales del proceso fotográfico.

Al morir Hipalia, su pariente descubre que, en realidad, su imagen había sido impresa en el muro del subterráneo en que se miraba. El narrador comenta que tuvo que cerciorarse por sus propios ojos, para luego comprobar que lo que allí había era "la esfigie viva de Hipalia, o mejor dicho, Hipalia misma en la inmaterialidad de su última belleza” (183). Para reafirmar la idea de una imagen vívida de la joven, el narrador asegura que la impresión en el muro no era un retrato, sino la realidad misma. Para comprobarlo, toca la mejilla de Hipalia y la siente tibia. La última palabra del cuento, es una interrogación: “...¿Muerta?...” (183). El narrador se pregunta, confundido, acerca del estado real de la joven supuestamente fallecida. ¿Puede una imagen estar más viva que el modelo que la produjo? Es la pregunta que sirve de premisa a este cuento. La hipótesis subyacente a esta ficción radica en la idea de traspaso, que se produce a través de un proceso que involucra la pose. Batchen ha afirmado que la pose es, en realidad, un tipo de muerte lenta, en que el modelo adquiere desde el comienzo una postura mortuoria. En los comienzos de la fotografía, la prensa fue la primera en notar que la fotografía era incapaz de reproducir el movimiento. Esta incapacidad se debía en parte al prolongado tiempo de exposición que se requería para obtener fotografías (Batchen 135). La pose requerida para daguerrotipos y las primeras fotografías, por ejemplo, requería el uso de aparatos que servían de apoyo a los modelos, como el appui-tête y el appui-tronc, que debían permanecer invisibles para el éxito de la impresión (Sougez 84). Este tipo de procedimientos llevó a Walter Benjamin a comparar el estudio fotográfico con una cámara de tortura. Batchen por su parte, concluye que este tipo de instrumento utilizado para lograr la inmovilidad del modelo en realidad tranformaba el cuerpo vivo en una esfinge embalsamada, como una momia. En el cuento de Lugones, el proceso de la pose absorbe la imagen viva de Hipalia y como resultado, ella es descrita con las cualidades de un fantasma o una aparición. Su imagen impresa, en cambio, posee toda la vida que a la Hipalia real le falta. El carácter fantástico de este cuento puede relacionarse con las creencias sobrenaturales que surgieron a comienzos de la historia de la fotografía. El fotógrafo francés Paul Nadar describió el caso del novelista Honoré de Balzac, quien temía y evitaba a toda costa ser fotografiado: 
According to Balzac's theory, all physical bodies are made up entirely of layers of ghostlike images, an infinite number of leaflike skins laid one on top of the other. Since Balzac believed man was incapable of making something material from an apparition, from something impalpable-that is, creating something from nothing-he concluded that every time someone had his photograph taken, one of the spectral layers was removed from the body and transferred to the photograph. Repeated exposures entailed the unavoidable loss of subsequent ghostly layers, that is, the very essence of life. (Batchen 208)

Aquí puede establecerse un paralelo directo con la "Hipalia” de Lugones. Tal como lo describe Balzac, la figura de Hipalia fue desprendiéndose de sus capas paulatinamente en el proceso de la pose. Esto le significó lo más temido por el novelista: la pérdida de la vida. Por otra parte, se dice que el personaje de Hipalia perdió la razón: el narrador dice que “se volvió loca de orgullo” por su belleza, y que se vestía siempre de blanco (181), “el color de los locos fatales” (182), que iba a ver su imagen en el subterráneo, “jardín de su locura” (182), mientras “íbase consumiendo en aquella pacífica idiocia que ni siquiera constituía una contemplación” (182). Tal como lo indica Tom Gunning, las fotografías faciales tuvieron un lugar especial en el tratamiento de los enfermos mentales y contribuyeron al estudio de las enfermedades como un modo de clasificarlas (12). En "Hipalia" encontramos un sujeto femenino fotografiado metafóricamente, que se transforma en un objeto de potencial estudio médico. Desde el punto de vista social, al enloquecer Hipalia, se vuelve un sujeto doblemente peligroso, puesto que es mujer y además, pierde el juicio. En su ensayo sobre las ficciones paranoicas y el naturalismo argentino, Gabriela Nouizelles destaca la idea de que los proyectos nacionales tenían como imperativo el actuar sobre algunos grupos de la sociedad que supuestamente podían desestabilizar el proyecto modernizador por su comportamiento social y económico. Entre ellos estaban los mestizos, los negros, las mujeres y los inmigrantes. A estos grupos se agregó, además, el de los enfermos mentales, destacándose enfermedades de moda como la histeria y la neurastenia. Estas enfermedades provocaban una ansiedad especial porque, por una parte anulaban el orden de la racionalidad y por otra, su desarrollo era lento e imperceptible (237).

Los personajes de estos cuentos de Lugones se identifican con el sujeto occidental moderno en su afán de conseguir riquezas y conocimiento: son el aficionado a las ciencias, el científico, el colonizador, el técnico o el comerciante. Los narradores por su parte-todos en primera persona- son testigos oculares de un fenómeno extraño que intentan primero desentrañar y luego comunicar, mezclando elementos científicos, seudocientíficos e incluso mágicos en su descripción. Ellos sienten una atracción y a la vez un miedo inexplicable ante lo que observan y narran. En general, el miedo que experimentan se relaciona con la inestabilidad del sujeto como un ente único (el miedo a la reproducción o doblaje) y con la posibilidad de perder la vida en el proceso (la fotografía como medio de la muerte). La fotografía aparece como un dispositivo de reproducción mecánica que actúa de manera inquietante, puesto que cuestiona las ideas preestablecidas en relación a la formación de sujetos. La fotografía -que como medio funciona como evidencia y que supone tener un efecto identificador de los sujetos-, en realidad contribuye a crear miedo a la duplicación, a la división y a la pérdida de la identidad. 
En otro nivel interpretativo, a pesar de que en estos cuentos no hay una referencia explícita a la nación, sí puede observarse cómo estos cuentos proponen un mapa en que Argentina se ubica dentro del contexto mundial. El inglés de "Un fenómeno inexplicable" viaja a la India y luego a la Argentina; el espejo de "Los ojos de la reina” es egipcio, pero termina en el Museo Etnográfico de este país sudamericano. Por otra parte, el sujeto propuesto en estos cuentos -identificado con el narrador en primera persona- intenta desesperadamente constituirse en relación a un otro que toma la posición del objeto representado. Éste aparece respectivamente como un colonizador/inmigrante, un criminal, una reina exótica reflejada en un espejo (una pieza de museo), o como una joven que pierde la razón al contemplarse.

En conclusión, la fotografía aparece en estos cuentos de Lugones como un elemento desestabilizador y desidentificatorio, que genera atracción y rechazo a la vez. Si contextualizamos esta producción de finales del siglo xIx y principios del xx, encontramos que las nuevas tecnologías de reproducción contribuyeron a crear una idea de nación de manera indirecta, al fotografiar el cuerpo del "otro" que comenzaba a habitar el espacio argentino y generaba ansiedad. No es raro que Lugones, un escritor de la generación del centenario, de ideas políticas contradictorias, interesado en las ciencias y en el origen y destino de la nación argentina, escribiera estos cuentos que -aunque fantásticos-revelan sus propias ansiedades y preocupaciones, como también las de su época.

\section{Bibliografía}

Alloula, Malek. "From The Colonial Harem”. The Visual Culture Reader. Nicholas Mirzoeff, ed. Londres y Nueva York: Routledge, 1999. 317-22.

Barthes, Roland. Camera Lucida. Richard Howard, trad. Nueva York: Hill \& Wang, 1981. Batchen, Geoffrey. Burning with Desire. 2nd ed. Cambridge: MIT UP, 1999.

Becquer Casaballe, Amado y Miguel Ángel Cuarterolo. Imágenes del Río de la Plata. Crónica de la fotografía rioplatense 1840-1940. Buenos Aires: Editorial del Fotógrafo, 1983.

Eaton, George T. "History of Processing and Image Stability”. Pioneers of Photography. Their Achievements in Science and Technology. Eugene Ostroff, ed. Springfield: The Society for Imaging Science and Technology, 1987.

Freund, Gisèle. La fotografía como documento social. Josep Elias, trad. Barcelona: Gustavo Gili, 2002.

Gasparini, Sandra y Claudia Román. “Fauna académica: las ‘calaveradas perdonables’de Eduardo Holmberg”. Eduardo L. Holmberg. El tipo más original y otras páginas. Buenos Aires: Simurg, 2001. 185-218.

Gunning, Tom. "In Your Face: Physiognomy, Photography, and the Gnostic Mission of Early Film”. Modernism/Modernity 4/1 (1997): 1-29.

Haraway, Donna. Primate Visions: Gender, Race, and Nature in the World of Modern Science. London: Routledge, 1989.

Jenkins, Reese. “Science, Technology, and the Evolution of Photography, 1790-1925”. Pioneers of Photography. Their Achievements in Science and Technology. Eugene Ostroff, ed. Springfield: The Society for Imaging Science and Technology, 1987. 
Kay, Ronald. Del espacio de acá. Señales para una mirada americana. Santiago: Editores Asociados, 1980.

Lugones, Leopoldo. Las fuerzas extrañas. Arturo García Ramos, ed. Madrid: Cátedra, 1996.

Cuentos fantásticos. Pedro Luis Barcia, ed. Madrid: Castalia, 1987.

Marún, Gioconda. "Darwin y la literatura argentina del siglo XIX”. Actas del XII Congreso de la Asociación de Hispanistas: 21-26 de agosto de 1995. Birmingham: Dept. of Hispanic Studies, University of Birmingham, 1988. 82-91.

McElroy, Keith. Early Peruvian Photography. A Critical Case Study. Ann Arbor: UMI Research Press, 1985.

Nouzeilles, Gabriela. "Ficciones paranoicas de fin de siglo: naturalismo argentino y policía médica”. MLN 112/2 (1997): 232-52.

Poole, Deborah. Vision, Race and Modernity. Princeton: Princeton UP, 1997.

Sarlo, Beatriz. La imaginación técnica. Buenos Aires: Nueva Visión, 1992.

Skidmore, Thomas E. y Peter H. Smith. Modern Latin America. Nueva York: Oxford UP, 1984.

Sontag, Susan. On Photography. Nueva York: Farrar, Straus and Giroux, 1977.

Sougez, Marie-Loup. Historia de la fotografía. Madrid: Cátedra, 2001. 